\title{
Level of Internet Addiction of Schoolchildren and Specific Character of Their Socio- Psychological Adaptation
}

\author{
Galina Kozhukhar ${ }^{1, *}$ and Alla Belousova ${ }^{2}$ \\ ${ }^{1}$ Moscow State University of Psychology and Education, Sretenka st,29, 127051 Moscow, Russia \\ ${ }^{2}$ Don State Technical University, Gagarin sq, 1, 344003 Rostov- on-Don, Russia
}

\begin{abstract}
This article is devoted to the study of the characteristics of socio-psychological adaptation of high school students with different levels of Internet addiction. The paper examines the phenomenon of Internet addiction as a variation of behavioral addiction in the context of information security. The study involved 120 high school students from municipal educational institutions in Moscow. Two diagnostic methods were used: Chen Internet Addiction Scale - CIAS adapted by V.L. Malygina, K.A. Feklisova; Test of Personal Adjustment by Carl R. Rogers, Rosalind F. Dymond (adapted by A.K. Osnitsky). As a result of the conducted empirical research, significant differences in the components of socio-psychological adaptation of schoolchildren with different levels of Internet addiction have been shown; it has also been proved that Internet addiction acts as a predictor of adaptation of high school students.
\end{abstract}

\section{Introduction}

Security is a central aspect to today's debates about human health, loss prevention, environmental protection, sustainability and greener manufacturing. In the information era, especially in the era of big data, knowledge about the information security is an important strategy for ensuring it. The issues of not only creating models of information security, but also managing the information flows with the aim of preserving the intellect, personality and one's health in a broad sense, are becoming more and more fundamental [1-4].

Current research provides compelling evidence of a direct interrelation between online addictions and mental health problems across cultures. Moreover, Internet addictions are mainly common among adolescents and university students. For example, in East Asia (China, Japan, South Korea), the prevalence of generalized Internet addiction varied from $12.6 \%$ to $67.5 \%$. A meta-analysis of 64 studies allowed us to identify a range of risk factors associated with online addictions, such as psychological distress, mood disorders, suicidality, impulsivity, aggression, and sleep problems [5].

Due to the widespread use of the Internet in its various versions, the question of information security arises and it still remains open. Its answer is especially important, since the Internet attracts younger users and this age related bar is decreasing every year.

* Corresponding author: kozhuhargs@mgppu.ru 
At the moment, it becomes irrefutable that the impact that the Internet can have on a person is stronger than the impact of any other technical system, and the expansion of its capabilities increases this impact every day. Together with the massive opportunities that the Internet environment provides, the question of Internet addiction arises.

Dependence or addiction is an inadequately high susceptibility to any given external influence, as a rule, due to a personal inability to withdraw from the effect as a result of such an influence. Generalized internet addiction (GIA) is a broad term that can encompass and not distinguish between a number of specific online addictions, such as gaming disorder, pornographic addiction, Internet gambling addiction, and social media addiction. According to the bio-psychosocial model of addictions, it includes symptoms of behavioral addictions, in particular, severity of mood changes, tolerance, withdrawal, conflict and relapse, causes serious problems in daily life, alongside associated psychiatric symptoms, bipolar and personality disorders. GIA and its various subforms have been associated with symptoms of substance-related disorders, depression, anxiety, as well as social anxiety, loneliness [6-7].

The Internet environment, while providing new opportunities, also generates a special cultural space in which the subject of influence is drawn into new types of activities that mediate the formation of the self-image. Thus, cyberculture - the culture of presenting information and communication on line, can, in particular, be considered as a means of mediating the formation of socialization and, consequently, self-awareness.

The answer to the question is controversial: whether the Internet itself is an addictive agent, or it acts as an intermediary for the implementation of other dependencies. Shaffer co-authors argue the existence of two phenomena at the same time - the Internet is a means of achieving addictive content with already formed addiction and exists in an independent form of addiction [8].

Dependence on the Internet directly is determined by the fact that most addicts use those Internet functions that are absent outside of this environment - for example, social networks or online games.

As a rule, those who become Internet addicts change their personality. First, addicts are characterized by a change in addictive implementation. Today he is an Internet addict, tomorrow he is a love addict, the day after tomorrow he is a pathological gambler, and after a while he switches to drug addictions. Secondly, the danger lies in the fact that very often, sooner or later, addictive individuals become socially maladjusted. Internet addiction, causing the development of psychological changes in personality, can lead to antisocial behavior $[9 ; 10]$.

The Internet can be considered a new social environment that develops and changes, attracting an increasing number of users, more of whom are adolescents and young adults. Along with this, the question of Internet addiction as a specific type of behavioral addiction arises.

Therefore, adolescents and young adults, who are attracted by unlimited freedom, lack of responsibility, the presence of mystery and anonymity, become the risk group for Internet addiction. The study of Internet addiction among adolescents requires special attention, since this age is quite important for the formation of a personality, gaining a sense of adulthood, and adequate perception of oneself and the environment. Also, the violation of interpersonal interactions, both with peers and adults, contributes to the escape of adolescents from problems into a virtual environment, where it is easier for them to adapt and be whoever they want. An internal conflict may be formed, caused by contradictions between the requirements of other people and their own capabilities, such conflict, violating emotional comfort, inhibits the harmonious development of the personality, which, in turn, can also lead to the development of addictive behavior. 
Adolescents with established Internet addiction have disturbances in the emotional sphere, which are expressed in unawareness of their emotions, in the inability to express them, in restraint, suppression of emotions, therefore they avoid direct contacts and go where they feel comfortable and safe, i.e. in the Internet.

Many believe that high school students are more likely to use the Internet via mobile devices than other groups of people, the influence of which is evident in their social life, family relationships and friendships. The negative and/or positive impact of the Internet on schoolchildren and their lives is an important area of research. Important factors that may be associated with the emergence of such dependence are socio-demographic data.

The results show that the impact of the environment and students' grades on their Internet addiction is very limited. The reason for this result may lie in the fact that there is no direct correlation between the increase in the level of education and the variety of fields of activity of students. According to the results of the educational level of parents, it also does not have a direct effect on Internet addiction. This shows that the use of the Internet is directly related to the behavior, and not to the level of education of the person. The study authors conclude that the number of objects students receive from the Internet and access them over and over again throughout the day leads to Internet addiction among students. Finally, the fact that students do not think about the Internet during their daily tasks and prefer to spend time outdoors with their friends is a positive factor in terms of reducing the level of Internet addiction [11].

Some psychologists believe that modern young adults and adolescents will not be just addicted to the Internet, but have a different system of mental functioning, as they get used to interacting with the virtual world as with the real one.

Taking into account the fact that Internet users currently give more preference to Internet services, which are associated, in most cases, with communication, we assumed the existence of difficulties in real life associated with socio-psychological adaptation.

\section{Materials and Methods}

The main aim of the research was to identify the interrelations between the level of Internet addiction and the socio-psychological adaptation of high school students.

Research hypotheses:

1) high school students with different levels of Internet addiction will differ in the characteristics of socio-psychological adaptation;

2) the level of Internet addiction will be a predictor of the adaptation of high school students and vice versa.

To implement the aims and objectives, as well as to test the hypotheses put forward, the following psychodiagnostic research methods were used in the work.

Chen Internet Addiction Scale (CIAS) adapted by V.L. Malygina, K.A. Feklisova is a reliable diagnostic method that allows you to determine the level of Internet addiction with a high degree of reliability. The sum of all scales is an integral indicator of Internet dependence. CIAS identifies a number of scales (compulsive symptoms), (withdrawal symptoms), (tolerance symptoms), (intrapersonal and health problems), (time management problems), but in this work we used only the general, final indicator of Internet addiction. The levels of Internet addicted behavior are as follows: from 27 points to 42 - none; 43 - 64 points - propensity to develop Internet-dependent behavior / pre-addictive stage; finally, from 65 points and above - a statement of Internet-dependent behavior (behavior with a component of Internet abuse) [12-13].

Test of Personal Adjustment (TPA) by Carl R. Rogers and Rosalind F. Dymond adapted by A.K. Osnitsky 
It is used as an indicator of the socio-psychological adaptation-maladjustment of the personality in interpersonal relations. Questionnaire subscales: adaptability, maladjustment, self-acceptance, self-rejection, acceptance of others, rejection of others, emotional comfort, emotional discomfort, internal control, external control, dominance, submissiveness, escapism. Integral scales: adaptation, self-acceptance, acceptance of others, emotional comfort, internality, striving for domination are calculated according to the appropriate formulas (in this article, the calculation of integral scales, except for adaptation, was not described) [14-15].

The sample consisted of schoolchildren from $10^{\text {th }}$ grades (the study was conducted in the winter of 2020 , before the beginning of measures related to the coronavirus). It involved 120 students of city municipal schools, aged 15-16, among them 63 girls (52.5\%) and 57 boys $(47.5 \%)$.

For the purpose of statistical data processing, we used frequency, variance and regression analysis (SPSS, v. 23).

\section{Results}

According to the criterion of the level of Internet addiction, we identified the following three groups of subjects (Table 1). Schoolchildren made up three groups of subjects $22.5 \%$ (27 people) subjects with a pronounced and stable Internet addiction; students with a tendency to develop Internet addiction - 53.3\% (64 people); and subjects, 24.2\% (29 people) - who have a minimal risk of developing Internet addictive behavior.

Table 1. Distribution of schoolchildren by levels of Internet addiction

\begin{tabular}{lclll}
\hline The level of internet addiction & Frequency & Percentage & Valid \% & Cumulative \% \\
Pronounced Internet addiction & 27 & 22.5 & 22.5 & 22.5 \\
$\begin{array}{l}\text { Disposition to Internet } \\
\text { addiction }\end{array}$ & 64 & 53.3 & 53.3 & 75.8 \\
$\begin{array}{l}\text { Lack of Internet addiction } \\
\text { Total }\end{array}$ & 29 & 24.2 & 24.2 & 100.0 \\
\hline
\end{tabular}

To identify significant differences between subgroups of schoolchildren with different levels of Internet addiction, analysis of variance was applied, which allows to compare groups that are unequal in number. Its results are presented in Table 2.

The most significant differences between the three subgroups can be seen in such characteristics of socio-psychological adaptation as maladjustment, self-rejection, emotional discomfort and external control. Adaptability, self-acceptance, rejection of others, internal control, submissiveness and escapism also differ in severity. No differences were found in the manifestation of acceptance of others, the experience of emotional comfort and dominance.

In order to study whether the level of Internet addiction can be a predictor of the characteristics of socio-psychological adaptation, as well as whether adaptation is a predictor of addiction, we used regression analysis, which makes it possible to predict the values of the dependent variable based on the characteristics of the independent indicator, and evaluate the contribution of independent variables to the manifestation of the dependent characteristic.

Table 2. Analysis of variance: differences in the components of socio-psychological adaptation among schoolchildren with different levels of Internet addiction 


\begin{tabular}{|c|c|c|c|c|c|c|c|c|}
\hline 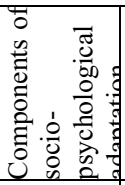 & 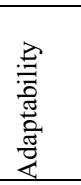 & 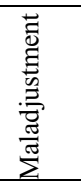 & 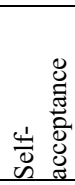 & 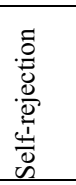 & 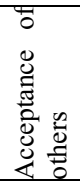 & 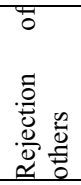 & 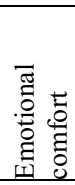 & 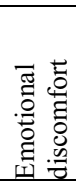 \\
\hline $\mathrm{F}$ & 5.18 & 20.13 & 6.37 & 19.75 & 0.99 & 4.63 & 1.51 & 22.78 \\
\hline Sig. & 0.007 & 0 & 0.002 & 0 & 0.377 & 0.012 & 0.226 & 0 \\
\hline
\end{tabular}

\begin{tabular}{|c|c|c|c|c|c|}
\hline 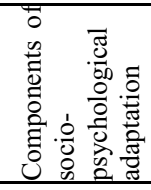 & 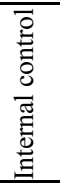 & 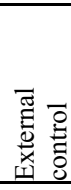 & 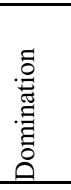 & $\begin{array}{l}0 \\
0 \\
0 \\
0 \\
.0 \\
0 \\
0 \\
0 \\
0 \\
0 \\
0 \\
0\end{array}$ & 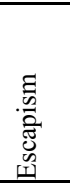 \\
\hline $\mathrm{F}$ & 4,75 & 15,12 & 0,1 & 4,09 & 7,08 \\
\hline Sig. & 0,01 & 0 & 0,872 & 0,019 & 0,001 \\
\hline
\end{tabular}

It turned out that the level of addiction makes it possible to predict the degree of experience of emotional discomfort and comfort (stepwise regression analysis) $\left(\mathrm{R}^{2}=0.311\right.$; $\mathrm{F}=26.454 ; \mathrm{t}=4.255 ; \beta=0.854$, with $\mathrm{p}=0.000 ; \mathrm{t}=-2.359 ; \beta=-0.623$, with $\mathrm{p}=0.020)$. The data suggest that the higher the level of addiction, the higher the emotional discomfort and the lower the experience of emotional comfort. We selected this indicator because, when performing stepwise regression analysis, emotional discomfort was found to be the only predictor of the level of addiction (although all components were included) $\left(\mathrm{R}^{2}=0.279 ; \mathrm{F}=\right.$ $45.580 ; \mathrm{t}=6.571 ; \beta=0.528$ with $\mathrm{p}=0.000$ ). As emotional discomfort rises, the tendency towards internet addiction increases.

Also, the level of addiction acted as a predictor of adaptability $\left(\mathrm{R}^{2}=0.042 ; \mathrm{F}=5.230 ; \mathrm{t}\right.$ $=-2.287 ; \beta=-0.206$, with $\mathrm{p}=0.024)$; and, accordingly, maladjustment $\left(\mathrm{R}^{2}=0.253 ; \mathrm{F}=\right.$ 40.002; $\mathrm{t}=6.325 ; \beta=0.503$, with $\mathrm{p}=0.000$ ).

Considering the influence of adaptability and maladjustment as predictors of the level of addiction, it was shown that maladjustment is the main factor in the growth of addiction $\left(\mathrm{R}^{2}\right.$ $=0.253 ; \mathrm{F}=40.002 ; \mathrm{t}=6.325 ; \beta=0.503$, with $\mathrm{p}=0.000$ )

The integral indicator of adaptation, as the results showed, can be predicted by the level of addiction development $\left(\mathrm{R}^{2}=0.219 ; \mathrm{F}=33.037 ; \mathrm{t}=-5.748 ; \beta=-0.468\right.$, with $\left.\mathrm{p}=0.000\right)$ : the lower the addiction, the more successful the adaptive processes

\section{Discussion and Conclusions}

These results allow us to draw conclusions about the importance of studying the phenomenon of Internet addiction, since the number of Internet addicted high school students and the number of those predisposed to it is $75.8 \%$ of the total number of subjects. The number of students who have already formed stable Internet addiction is slightly smaller in comparison with those who have no addiction at all. Most of all schoolchildren turned out to be prone to the emergence of Internet addiction, that is, those who are at risk and require increased attention, no less than the group of subjects with pronounced Internet addiction.

Summarizing all the results of our study, we can draw up three socio-psychological portraits: an average schoolchild with a pronounced Internet addiction, with a tendency to Internet addiction and with no Internet addiction.

The characteristics of the average high school student with a pronounced Internet addiction are characterized by a high level of maladjustment and low adaptation, higher level of escapism in comparison with other subgroups, rejection of oneself and others, low 
experience of emotional comfort, low indicator of internality (dominance of external control over internal) and a tendency to submissiveness.

One study involved 250 undergraduate students and was statistically analyzed using structural equation modeling with partial least squares. The results show that entertainment, social networking sites, and game-related use have a positive effect on smartphone addiction. While study-related use has a positive effect on academic performance, gamerelated use has a negative effect. In addition, physical activity reduces the negative impact of game-related use on academic performance. The findings expand the literature on smartphone addiction by introducing physical activity as a preventative factor and will be useful for policymakers and parents to understand the importance of developing and promoting physical activity among young people. In addition, overuse of smartphones by students can negatively impact their academic performance and learning activities, especially for universities, where there is a lot of independence in regulating how and when to use smartphones. Scientific studies have also found that constant testing of students and overuse not only negatively affect their learning, but also have negative effects on their health, such as pain in the wrists, blurred vision, low self-esteem, anxiety, insomnia and poor eyesight [16-18].

High school students with a tendency to Internet addiction due to their middle position have less pronounced indicators than the polar groups with no Internet addiction and pronounced Internet addiction, and combine the characteristics of both groups. The schoolchildren who made up this group have a low level of socio-psychological adaptation, which consists of the desire to avoid problems, low indicators of acceptance of oneself and others, mean level of emotional comfort, low level of externality, that is, external control prevails over internal, but not so clearly as with a pronounced Internet addiction, there is also a tendency to submissiveness.

A subgroup of high school students with no Internet addiction has a higher sociopsychological adaptation, which consists of a low indicator of maladjustment and a high indicator of adaptability, a low level of escapism, a high level of acceptance of oneself and others, low emotional discomfort, the prevalence of internal control over external control, and as a consequence, they are characterized by a high level of internality and a low level of submissiveness, i.e. they have a more pronounced desire to dominate.

A study that had been conducted in Taiwan for 12 months, the purpose of which was to analyze the reversibility of Internet addiction appears to be rather interesting. Internet addiction was defined as indicator on Chen Internet Addiction Scale (CIAS) $>63$. Validated indicators were used to assess students' psychosocial well-being at baseline and subsequent periods. The results showed that of 1545 students with Internet addiction as baseline, 1296 (83.9\%) provided comparable baseline (12-month) observation data, which were analyzed. The remission rate (CIAS $\leq 63$ with follow-up observation) was 59.29 per 100 person-years. Significant predictors included: 1) baseline CIAS score 2) baseline health belief model, addiction susceptibility constructs, perceived barrier, parenting behavior, and self-efficacy to reduce Internet use. Baseline psychosocial health indicators (self-esteem, severe depression, social anxiety, loneliness) and their changes over time, and family support were also taken into account. Two-thirds $(64.3 \%)$ of patients in the remission group had a reduced CIAS score $>1.5 \mathrm{SD}$ and recorded better improved psychosocial status over time than in the non-remission group [19].

Thus, Internet addictions interfere with everyday life, affecting mental health, emotional well-being, academic performance, work and social interactions.

\section{Implications for Practice}


Internet addiction is a real phenomenon. Many psychologists believe that the Internet is primarily an information resource, but for many people it has turned into the main environment of their activity - a place where they communicate and build close relationships, a place with which expectations and disappointments are associated, a place where you can hide from the present. Such appealing characteristics of the Internet attract adolescents and young adults who are going through an important stage of personality formation, looking for their place in the world and experiencing the burden of responsibility of the upcoming adult life.

In the course of the study, we identified a connection between Internet addiction and the socio-psychological adaptation of high school students and such components as maladjustment, acceptance of oneself and others, emotional discomfort, externality, escapism, and the desire for submission. Based on the data obtained, three portraits of the average high school student with different levels of Internet addiction were described.

In order to help students with addiction, it seems productive to develop their ability for individual information security behavior on the basis of a conceptual model for the development of this ability. Wang and $\mathrm{Wu}$ built a metamodel of information security behavior, which includes the choice and demand for secure information, motivation aimed at selectivity of secure information, security of search information behavior, and, finally, information utilization that ensures security behavior [20-21].

The cognitive-behavioral approach of counseling and therapy has also been shown to be effective in working with addictions, although other interventions have also been shown to be effective in reducing symptoms of addiction. Of course, further research is needed, as well as the development and implementation of strategies for the prevention and treatment of Internet-addicted schoolchildren.

\section{References}

1. B. Wang, C. Wu, Safety informatics as a new, promising and sustainable area of safety science in the information age. Journal of Cleaner Production, 252, 119852 (2020)

2. I. Abakumova, A. Grishina, G. Zvezdina, E. Zvezdina, E. Dyakova, Models of information behavior: Changes in psychological boundaries of internet users, E3S Web of Conferences, 210 (2020) https://doi.org/10.1051/e3sconf/202021020015

3. B.N. Cvetković, L. Stošić, A. Belousova, Media and Information Literacy - the Basis for Applying Digital Technologies in Teaching from the Discourse of Educational Needs of Teachers, Croatian Journal of Education, 20(4), 1089-1114 (SKOPUS) (2018) https://doi.org/10.15516/cje.v20i4.3001 (Web of Science).

4. G. Kozhukhar, Representations of university students about psychological safety of educational environmental, 11th International Technology, Education and Development Conference, 6-8, 3473-3478 (Valencia, Spain, 2017) https://doi.org/10.21125/inted.2017.0868 (Web of Science).

5. D. Kuss, A.M. Kristensen, O. Lopez-Fernandez, Internet addictions outside of Europe: A systematic literature review. Computers in Human Behavior, 115, 106621 (2021)

6. D.J. Kuss, O. Lopez -Fernandez, Internet addiction and problematic internet use: A systematic review of clinical research. World Journal of Psychiatry, 6(1), 143-176 (2016)

7. J.T.F. Laua, A.M.S. Wuc, D.L. Grossa, Kit-man Chenga, M.M.C. Laua, Is Internet addiction transitory or persistent? Incidence and prospective predictors of remission of Internet addiction among Chinese secondary school students. Addictive Behaviors, 74, 55-62 (2017) 
8. H.J. Shaffer, M.N. Hall, J. Vander, J. Bilt, "Computer addiction": a critical consideration. Am J Orthopsychiatry, 70(2), 162-8 (2000)

9. A. Fumero, R.J. Marrero, D. Voltes, W. Peñate, Personal and social factors involved in internet addiction among adolescents: A meta-analysis. Computers in Human Behavior, 86, 387-400 (2018)

10. N. Simsek, D. Sahin, M. Evli, Internet addiction, cyberbullying, and victimization relationship in adolescents: A sample from Turkey. Journal of Addictions Nursing, 30(3), 201-210 (2019)

11. E. Tekkanat, M. Topaloglu, The Assessment of High Schoolers' Internet Addiction. Procedia - Social and Behavioral Sciences, 205, 664 - 670 (2015)

12. Y. Chen, S.S. Peng, University students' Internet use and its relationships with academic performance, interpersonal relationships, psychosocial adjustment, and selfevaluation. Cyberpsychology \& Behavior, 11, 467-469 (2008)

13. J. Yen, C. Yen, C. Chen, T. Tang, C. Ko, The association between adult ADHD symptoms and internet addiction among college students: the gender difference. Cyberpsychology \& Behavior, 12, 187-191 (2009)

14. R.F. Dymond, Adjustment changes over therapy from self-sorts. Psychotherapy and personality change, 76-84 (University of Chicago Press, 1954)

15. R.F. Dymond, An adjustment score for Q sorts. Consult. Psychol, 5, 339-42. (1953)

16. G.A. Abbasi, M. Jagaveeran, Y.-N. Goh, B. Beenish Tariq, The impact of type of content use on smartphone addiction and academic performance: Physical activity as moderator. Technology in Society, 64, 101521 (2021)

17. S. Fu, X. Chen, H. Zheng, Exploring an adverse impact of smartphone overuse on academic performance via health issues: a stimulus-organism-response perspective, Behav. Inf. Technol. 1-13 (2020)

18. K.-M. Yang, The effect of self-esteem and depression on smartphone addiction among university students, J. Kor. Converg. Soc., 7(1), 113-123 (2016)

19. J.T.F. Laua, M.S. Anise, A. Wuc, D.L. Grossa, K. Chenga, M.M.C. Laua, Is Internet addiction transitory or persistent? Incidence and prospective predictors of remission of Internet addiction among Chinese secondary school students. Addictive Behaviors, 74, 55-62 (2017)

20. B. Wang, C. Wu, An outline of the research on safety-related information behavior: basic concepts, metamodel, research purport, research paradigm and research framework. Inf. Stud.: Theory Appl., 41(1), 43-49 (2018)

21. L. Huang, C. Wu, B. Wang, Individual behavioral safety mechanism and its influence factors based on information cognition. J. Intell., 37(8), 121-127 (2018) 